\title{
Retraction Note to: Correlation between amount-of-reuse metrics and other software measures with respect to programming code in $\mathrm{C}++$
}

\author{
Zaigham Mahmood $\cdot$ S. Tauseef Ur Rehman
}

(C) Springer Science+Business Media, LLC 2011

Retraction Note: Software Qual J (2003) 11:301-312

DOI 10.1023/A:1025865227964

This paper has been retracted due to plagiarism. The editor has determined that the paper is very similar to a conference paper published by other authors.

The online version of the original article can be found under doi:10.1023/A:1025865227964.

Z. Mahmood ( $\bowtie)$

Derbyshire Business School, University of Derby, Derby DE22 1GB, UK

e-mail: z.mahmood@derby.ac.uk

Z. Mahmood · S. Tauseef Ur Rehman

Department of Computer Science, International Islamic University, Islamabad, Pakistan 